\title{
Determining and Mapping Soil Nutrient Content Using Geostatistical Technique in a Durian Orchard in Malaysia
}

\begin{abstract}
Soil nutrient are essential for crop growth. Spatial variability of nutrient can be occurred in various scales, between region, field or within field especially in variation in soil properties. Precision farming is a technology currently available for sustainable agriculture. This technology enables farm management is based on small-scale spatial variability of soil and crop parameters in the field. This study was carried out in a Durian Orchard at Bendang Man Agrotourism Project, Sik, Kedah, Malaysia. The objectives of this study are to determine and map soil nutrient content especially Nitrogen, Phosphorus and Potassium (NPK) variability in a durian orchard using geostatistical technique. The NPK was analyzed and mapped by Geostatistic Plus (GS++) to quantify the level of spatial nutrient available and predict nutrient values at unsampled location. Results indicated that NPK ranged from $<0.1$ to $1.0 \%(\mathrm{~N}),<3$ to $>45 \mathrm{ppm}(\mathrm{P})$ and 0.8 to $>1.4 \mathrm{cmol}(+) / \mathrm{kg}(\mathrm{K})$, respectively. Nutrient map showed that the area has less sufficient of $\mathrm{N}$, while $\mathrm{P}$ and $\mathrm{K}$ were sufficient. This study revealed the potential and ability of geostatistical-variogram in determining and mapping soil nutrient content in a durian orchard. Furthermore NPK map can be used to apply fertilizer to an area, where less NPK content for efficient fertilizer management.
\end{abstract}

Keyword: Soil nutrient mapping, Precision farming, Soil nutrient analysis, Geostatistical technique, Durian orchard 